Original Article

\title{
Randomised, single blinded, controlled, prospective study comparing ketamine, lignocaine and chlorhexidine gargle in prevention of post-operative sore throat
}

\author{
Sumalatha R. Shetty ${ }^{1}$, Karan Pratap Singh Panaych ${ }^{2} \&$ Raveendra U.S. ${ }^{3}$ \\ ${ }^{1,3}$ Professor, ${ }^{2}$ Post Graduate, Department of Anaesthesiology, K.S. Hegde M edical Academy, \\ Nitte University, Mangalore, Karnataka, India. \\ Correspondence \\ Karan Pratap Singh Panaych \\ H. No. 2571, Sector 35-C, Chandigarh. (U.T.) 160022, India. \\ Mobile : +91 7411263255 E-mail : kpsp15@gmail.com
}

\begin{abstract}
Background : Postoperative sore throat is a common complaint in patients after extubation and can be distressing to the patients. Hence we aimed to compare efficacy of lignocaine, ketamine and chlorhexidine gargle for the control of postoperative sore throat.

Materials and Methods : After institutional ethical committee clearance, 100 patients were allotted into 4 groups of 25 each in this randomized, double blind, control study. The study solution for gargle in Group L, Group C and Group K contained 50mg lignocaine, $30 \mathrm{mg}$ chlorhexidine and $50 \mathrm{mg}$ ketamine in $30 \mathrm{ml}$ sterile water respectively while in Group W it was $30 \mathrm{ml}$ of sterile water. The study solution was given 5 minutes before induction and the patients were made to gargle it for 30 seconds. The post-operative sore throat (POST) grading was done at $0,2,6$ and 24 hours after extubation.

Results: At 0 hour, there was a significant lower grades of POST in Group Kas compared to Group W ( $p=0.011$ ). At the 4 hour interval, the grades of POST were significantly lower in group K $(p=0.001)$ and Group $L(p<0.001)$ whencompared to Group C.At the 24 hour time interval, the grades of POST were lower in Group L $(p=0.007$ ) and Group K ( $p \varangle 0.001$ ) when compared to Group C. At the same time interval, significantly lower grades of POST in Group W was seen compared to Group $C(p=0.001)$. At the end of all time intervals there was no statistical significant difference in the severity of POST in Group Land Group K. There were no significant haemodynamic changes in any of the groups.
\end{abstract}

Conclusion : Ketamine and Lignocaine gargles are effective in the reduction of postoperative sore throat without any changes in haemodynamics.

Keywords : Lignocaine, Ketamine, Chlorhexidine, Sorethroat

\section{Introduction}

Endotracheal intubation for general anesthesia often leads to trauma of the airway mucosa, resulting in postoperative sore throat (POST), cough, and hoarseness, with reported incidences of $21 \%-65 \%(1,2)$. These postoperative problems, although not incapacitating, can be irritating and at times distressing to the patients. Inspite of many

Access this article online

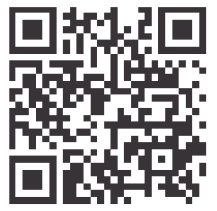

techniques attempted to reduce its incidence, POST still remains a common complaint in patients after extubation. Application of steroids to the portions of the endotracheal tube that contact the posterior pharyngeal wall, vocal cords, and trachea markedly reduce POST, hoarseness and cough(3).Though lignocaine spray can be used, the additives in it could cause POST in some patients (4). Recently, ketamine gargle has showed promise of reduction in the incidence of POST. Hence, we undertook a study to compare the effectiveness of preoperative oral gargling with ketamine, lignocaine, chlorhexidine in prevention of POST. We also planned to evaluate the effectiveness of preoperative oral gargling on prevention of POST in surgeries involving airway.

\section{Methodology}

In this randomised, double blind, controlled, prospective study, 100 patients aged 15-60 years scheduled to undergo elective surgery under general anaesthesia with oral 
intubation were divided into 4 groups of 25 each after Institutional ethical committee clearance and informed consent was obtained.

Patient aged above $60 \mathrm{yrs}$, with known history of sensitivity and contraindications to study drugs, history of significant co-morbidities and preoperative sore throat, patients who refused to participate were excluded from study. The gargle study solution in Group L, Group C and Group K contained $50 \mathrm{mg}$ lignocaine, $30 \mathrm{mg}$ chlorhexidine and $50 \mathrm{mg}$ ketamine in $30 \mathrm{ml}$ sterile water respectively while, Group W it was $30 \mathrm{ml}$ of sterile water.

After a thorough preoperative evaluation the patients were premeditated with tablet diazepam $10 \mathrm{mg}$ and tablet ranitidine $150 \mathrm{mg}$ at night before and morning of surgery with sips of water.

On the day of surgery, after patient was shifted into the operation theatre, standard ASA monitors were connected and OT personnel blinded to the drug, gave $30 \mathrm{ml}$ of study solution to the patient to gargle for 30 seconds. After 5 minutes, patients were preoxygenated for 3 minutes, and the particular procedure was carried out under general anaesthesia. Sterile, disposable polyvinyl chloride endotracheal tubes of same company (Portex) were used for all the patients. Endotracheal tubes of size 7-7.5 for adult females, 8-8.5 for adult male were used without lubricant, and cuff pressure was maintained between 25 to $30 \mathrm{~cm}$ of water throughout the procedure. Observations made during the study were number of intubation attempts, trauma during intubation, duration of surgery, duration of ETT in situ, head and neck movement after intubation, any change in the position of tube, presence of blood during throat suctioning at extubation. Intraoperative haemodynamics were monitored at baseline, five minutes after gargle, thereafter every five minutestill thirty minutes and then at extubation.

Patient was extubated after reversal of neuromuscular blockade after thorough oro-pharyngeal suction under vision.

The primary outcome measures were the postoperative

\section{sore throat based on four grades}

\begin{tabular}{|l|l|}
\hline 0 & No sore throat \\
\hline 1 & Mild sore throat ( c/o sore throat only on asking) \\
\hline 2 & Moderate sore throat ( c/o sore throat only on his/her own) \\
\hline 3 & $\begin{array}{l}\text { Severe sore throat (change of voice or hoarseness, } \\
\text { associated with throat pain) }\end{array}$ \\
\hline
\end{tabular}

The patients were interviewed in a standard fashion by a blinded investigator on arrival in the post-anaesthesia care unit $(0 \mathrm{~h}$ ) and at 2, 4, and $24 \mathrm{~h}$ thereafter for determination of POST.

\section{Statistical Analysis}

Taking prevalence of $65 \%$ of POST, study with power of $80 \%$ and a error at 5\%, 25 in each arm was calculated using n'master software used for calculation of sample size. One way anova test was used for comparison of variables. The Post HOC test was used for comparison of variables.

\section{Results}

The age and weight of the patients were comparable in all the groups. (Table 1)

In our study, at 0 hour, the grades of POST were significantly lower in the ketamine group than the placebo group. ( $p=0.011$ ) (Table2, Figure1)

At the 4 hour interval, the grades of POST were significantly lower in the lignocaine group $(p=0.001)$ and ketamine group ( $p<0.001)$ when compared to the chlorhexidine group. (Table 2, Figure 1)

At the $24 \mathrm{hr}$ interval even though the incidence of POST was lower with lignocaine group $(p=0.007)$ and the ketamine group ( $p<0.001$ ) compared to chlorhexidine group, there was a significantly lower overall grade of POST in the placebo group when compared to the chlorhexidine group.

(Table 2, Figure 1)

There was no significant difference between the groups in terms of haemodynamic changes intraoperatively. (Figure 2, Figure 3)

In our study, 20\%, 36\%, 28\% patients in lignocaine, ketamine, chlorhexidine group respectively, had surgeries involving airway. The incidence of POST in these subgroups was $80 \%, 77.77 \%$ and $57.14 \%$ respectively compared to placebo group proving no additional benefit of the gargle of these solutions in prevention of POST in these surgeries 
Table 1 : Patient demographics

\begin{tabular}{|l|l|c|c|c|c|c|c|}
\hline & & $\mathrm{N}$ & Mean & $\begin{array}{c}\text { Std. } \\
\text { Deviation }\end{array}$ & $\begin{array}{c}\text { Mean } \\
\text { Square }\end{array}$ & $\mathrm{F}$ & P VALUE \\
\hline Age & PLACEBO & 25 & 34.6 & 12.319 & 156.01 & 0.929 & 0.43 \\
\hline & LIGNOCAINE & 25 & 30.76 & 12.454 & & & \\
\hline & KETAM INE & 25 & 30.16 & 12.348 & & & \\
\hline & CHLORHEXIDINE & 25 & 34.92 & 14.586 & & & \\
\hline & Total & 100 & 32.61 & 12.948 & & & \\
\hline Weight & PLACEBO & 25 & 55.84 & 6.6 & 58.8 & 1.081 & 0.361 \\
\hline & LIGNOCAINE & 25 & 53 & 6.916 & & & \\
\hline & KETAM INE & 25 & 56.52 & 9.116 & & & \\
\hline & CHLORHEXIDINE & 25 & 55.46 & 6.521 & & & \\
\hline & Total & 100 & 55.2 & 7.383 & & & \\
\hline
\end{tabular}

Table 2 : POST Grades

\begin{tabular}{|l|l|c|c|c|c|c|c|}
\hline & & N & Mean & $\begin{array}{c}\text { Std. } \\
\text { Deviation }\end{array}$ & $\begin{array}{c}\text { Mean } \\
\text { Square }\end{array}$ & F & P VALUE \\
\hline POST G-0 & PLACEBO & 25 & 1.08 & 0.997 & 2.307 & 3.558 & $\underline{\mathbf{0 . 0 1 7}}$ \\
\hline & LIGNOCAINE & 25 & 0.8 & 0.816 & & & \\
\hline & KETAM INE & 25 & 0.36 & 0.569 & & & \\
\hline & CHLORHEXIDINE & 25 & 0.88 & 0.781 & & & \\
\hline & Total & 100 & 0.78 & 0.836 & & & \\
\hline & PLACEBT G-2 & 25 & 0.76 & 0.723 & 0.707 & 1.774 & 0.157 \\
\hline & LIGNOCAINE & 25 & 0.4 & 0.577 & & & \\
\hline & KETAM INE & 25 & 0.48 & 0.51 & & & \\
\hline & CHLORHEXIDINE & 25 & 0.68 & 0.69 & & & \\
\hline & Total & 100 & 0.58 & 0.638 & & & \\
\hline & PLACEBO & 25 & 0.2 & 0.408 & 1.317 & 8.02 & $\leq \mathbf{0 . 0 0 1}$ \\
\hline & LIGNOCAINE & 25 & 0.12 & 0.332 & & & \\
\hline & KETAM INE & 25 & 0.04 & 0.2 & & & \\
\hline & CHLORHEXIDINE & 25 & 0.56 & 0.583 & & & \\
\hline & Total & 100 & 0.23 & 0.446 & & & \\
\hline POST G-24 & PLACEBO & 25 & 0.04 & 0.2 & 0.667 & 7.477 & $\leq \mathbf{0 . 0 0 1}$ \\
\hline & LIGNOCAINE & 25 & 0.08 & 0.277 & & & \\
\hline & KETAM INE & 25 & 0 & 0 & & & \\
\hline & CHLORHEXIDINE & 25 & 0.36 & 0.49 & & & \\
\hline & Total & 100 & 0.12 & 0.327 & & & \\
\hline
\end{tabular}

\section{Discussion}

Postoperative sore throat (POST) is a minor complication that is unresolved in patients undergoing endotracheal intubation (7). POST was recently ranked by American anaesthesiologists as the eighth most important problem of current clinical anaesthesiology (5). POST following tracheal intubation is due to trauma to the airway mucosa. The reported incidence of POST varies from 21 to $65 \%$ (6). Various pharmacological and non- pharmacological trials have been used for attenuating POST with variable success.

In our study, at 0 hour, the grades of POST were significantly lower in the ketamine group than the placebo group. $(p=0.011)$
At the 4 hour interval, the grades of POST were significantly lower in the lignocaine group $(p=0.001)$ and ketamine group ( $p<0.001$ ) when compared to the chlorhexidine group.

At the 24 hour time interval, the grades of POST were lower in the lignocaine group $(p=0.007)$ and the ketamine group $(p<0.001)$ when compared to the chlorhexidine group while a significantly lower overall grade of POST was observed in the placebo group when compared to the chlorhexidine group. $(p=0.001)$

At the end of all time intervals there was no statistical difference in the severity of POST in the lignocaine and 
Fig. 1 : POST Grades

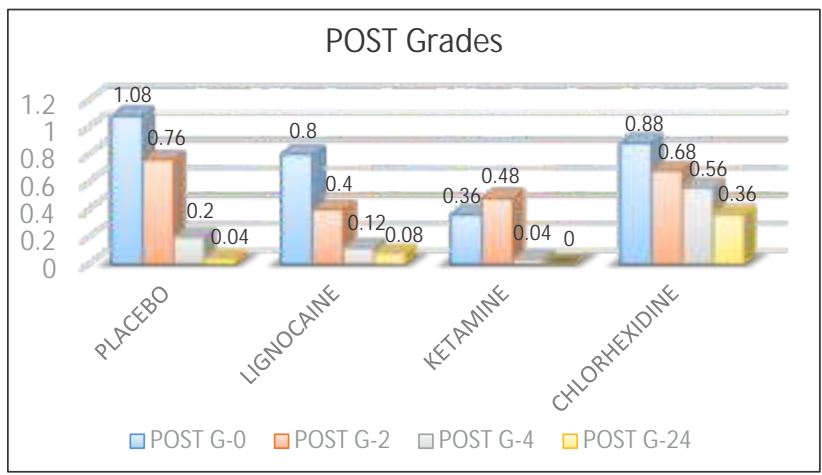

Fig. 3 : M ean arterial pressure

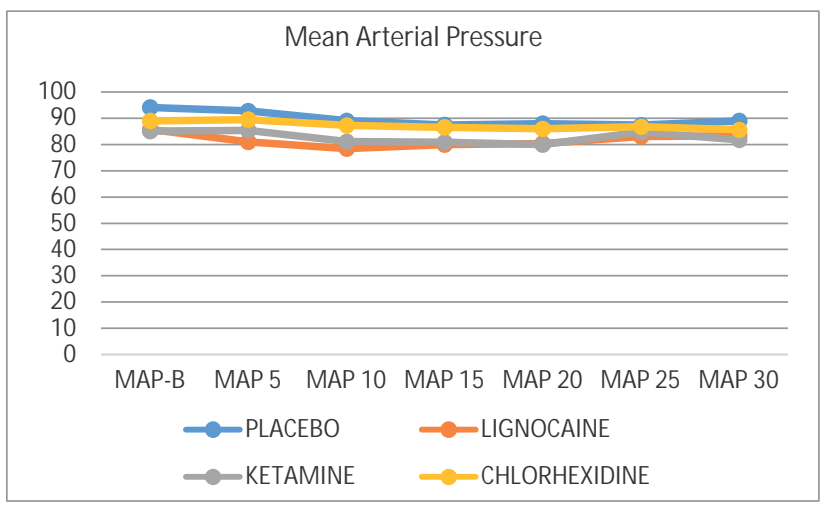

ketamine group in terms of grades of POST.

Even though lesser incidence of POST was noticed in the Ketamine, Lignocaine and Chlorhexidine group, gargling with ketamine before induction showed an overall decrease in the incidence of POST over 24 hours. Chlorhexidine, a commonly used oral gargle to maintain oral hygiene did not show any beneficial effect when compared to placebo.

Heart rate, M ean arterial blood pressure, oxygen saturation were comparable on most occasions in all the groups.

In our study there occurred more severe POST in the placebo group as compared to the ketamine group at 0,2 , 4 , and 24 hour time intervals and this was significant at the 0 hour interval. $(p=0.011)$. Similar results were seen in a study by Canbay 0 . et al in 2008, where he found that POST occurred more frequently in the control group, when compared with Ketamine group (gargle), at 0, 2, and $24 \mathrm{~h}$ and significantly more patients suffered severe POST in the control group at 4 and $24 \mathrm{~h}$ compared with the ketamine group $(\mathrm{P} \varangle 0.05)$. (8)
Fig. 2 : Heart rate

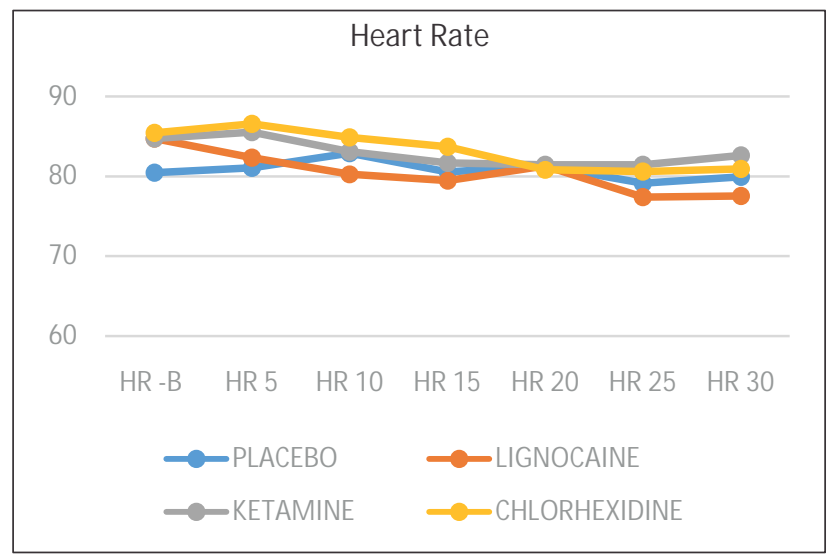

In our study, the severity of sore throat was significantly lower in the Lignocaine and Ketamine group than the chlorhexidine group at the 4 and 24 hour time interval.

Shabaan AR et al to o noticed the benefits of using ketamine as a gargle, when he found that the incidence and severity of sore throat were significantly lower with ketamine gargle and endotracheal tube lubrication with $0.05 \%$ betamethasone gel at all-time intervals in a randomized double blinded study. (9)

A. Rudra et al conducted a randomized study in 2009, where he found that POST occurred more frequently in the control group, when compared with patients belonging to Ketamine group (gargle), at 4, 8, and 24 hours and significantly more patients suffered severe POST in control group at 8 and 24 hours compared with Ketamine group. $(P \varangle 0.05)(10)$

However, Sumathi PA conducted a randomized blinded study in 2008, where they found that the incidence of postoperative sore throat, cough, and hoarseness of voice was significantly lower in the betamethasone group (jelly application on the endotracheal tube) compared with the other two groups (control group and lidocaine group)( $(\mathrm{P} \varangle$.05). (11)

At the 24 hour time interval, there was a significantly lower overall grade of POST in the placebo group when compared to the chlorhexidine group. $(p=0.001)$. In a study by Sun Yung Park et al in 2011, where they found that triamcinolone acetonide paste applied along the length of 
the ETT resulted in clinically important and statistically significant decreases in the incidence and severity of POST compared with the application of chlorhexidine jelly proving the no extra benefits of chlorhexidine.(12)

Chlorhexidine, a regularly used ingredient for mouth gargling, did not show any benefit in terms of preventing postoperative sore throat. The type of muscle relaxant used in the cases was not specified. Succinyl choline is a predictor of postoperative sore throat. (13). We however did not use it in our study.

\section{References}

1. Christensen AM, Willemoes-Larsen H, Lundby L, Jakobsen KB Postoperative throat complaints after tracheal intubation. $\mathrm{Br}$ J Anaesth 1994; 73:786-7.

2. Loeser EA, Benett GM, Orr DL, Stanley TH. Reduction of postoperative sore throat with new endotracheal tube cuffs. Anesthesiology 1980; 52:257-9.

3. Chakib M. Ayoub, MD, Ashraf Ghobashy, MD, Marc E. Koch, MD, Laura McGrimley, BA, et al. Widespread Application of Topical Steroids to Decrease Sore Throat, Hoarseness, and Cough After Tracheal Intubation. ANESTH ANALG. 715 1998; 87:714-6

4. K. Hara and K. Maruyama. Effect of additives in lidocaine spray on postoperative sore throat, hoarseness and dysphagia after total intravenous anaesthesia. ActaAnaesthesiologicaScandinavica. Vol 49 Issue 4, 463-467

5. Marcario A, Weinger $M$, Truong $P$, Lee $M$. Which clinical anesthesia outcomes are both common and important to avoid? The perspective of a panel of expert anesthesiologists. AnesthAnalg. 1999;88:1085-91

6. Christensen AM, Willemoes - Larsen H, Lundby L, Jacobsen KB Postoperative throat complaints after tracheal intubation. $\mathrm{Br}$ J Anaesth. 1994;73:786-7. [PubM ed]

7. M cHardy FE, Chung F. Postoperative sore throat: cause, prevention and treatment. Anaesthesia. 1999;54:444-53. [PubM ed]

8. O. Canbay, N. Celebi, A. Sahin, V. Celiker, S. Ozgen and U. Aypar Ketamine gargle for attenuating postoperative sore throat. British Journal of Anaesthesia 100 (4): 490-3 (2008)

9. ShaabanAR, Kamal SM. Comparison between betamethasone ge applied over endotracheal tube and ketamine gargle for attenuating postoperative sore throat, cough and hoarseness of voice. M iddle East

\section{Conclusion}

Ketamine and Lignocaine were more effective than Chlorhexidine in the prevention of postoperative sore throat.

\section{Acknowledgements}

I would like to thank Dr. Anand Bangera, Head of Department of Anaesthesiology and Critical Care, K.S. Hegde Medical Academy, Mangalore, for his constant support. I would also like to thank Dr. Soumya Rao for her participation and invaluable contribution to the study.

J Anaesthesiol. 2012 Feb;21(4):513-9

10. Rudra A, Ray S, Chatterjee S, Ahmed A, Ghosh S. Gargling with Ketamine Attenuates the Postoperative Sore Throat. Indian JAnaesth 2009:53:40-3

11. Sumathi PA, Shenoy T, Ambareesha M, Krishna HM. Controlled comparison between betamethasone gel and lidocaine jelly applied over tracheal tube to reduce postoperative sore throat, cough, and hoarseness of voice. Br J Anaesth. 2008 Feb;100(2):215-8.

12. Sun Young Park, Sang Hyun Kim, Se Jin Lee, Won SeokChae, HeeCheol Jin, JeongSeok Lee, Soon Im Kim, KyungHo Hwang. Application of triamcinolone acetonide paste to the endotracheal tube reduces postoperative sore throat: a randomized controlled trial. Can J Anaesth 2011 M ay 26;58(5):436-42.

13. P.P. Higgins, F. Chung, G. Mezei et al. postoperative sore throat after ambulatory surgery. Br] Anaesth. 2002; 88: 582-4.

14. Agarwal A, Gupta D, Yadav G, Goyal P, Singh PK, Singh U. An evaluation of the efficacy of licorice gargle for attenuating postoperative sore throat: a prospective, randomized, single-blind study.AnesthAnalg. 2009 Jul; 109(1):77-81.

15. Honarmand A1, Safavi M. Beclomethasone inhaler versus intravenous lidocaine in the prevention of postoperative airway and throat complaints: a randomized, controlled trial. Ann Saudi M ed. 2008 JanFeb;28(1):11-6.

16. Loeser EA, Bennett GM, Orr DL, Stanley TH. Reduction of post operative sore throat with new endotracheal tube cuffs. Anesthesiology. 1980;52:257-9.

17. M aruyama K, Sakai $H$, M iyazana $H$, et al. Sore throat and hoarseness after total intravenous anaesthesia. Br J Anaesth. 2004;92:541-3. 